\title{
ASYMMETRISM AND THE MAGNITUDES OF WELFARE BENEFITS
}

\author{
Andrew T. Forcehimes
}

7 HEORIES OF WELFARE need to address two central questions. First, they need to supply an account of what has value for you-i.e., what things are good for you or bad for you. More precisely, they need to answer the

Items-of-Value Question: What states of affairs are of basic intrinsic value for you?

For example, as usually understood, Desire Satisfactionism answers that the relevant state of affairs consists of two parts: the subject having a certain propositional attitude - a desire - and the obtaining of the object of that attitude. But even if Desire Satisfactionism answered this question correctly, we would still need an account of the amount a given satisfied desire contributes to your welfare. Put generally, theories of welfare need to say how much value a given episode of welfare has for you-i.e., the extent to which something is good for you or bad for you. More precisely, they need to answer a second question, namely, the

Magnitude-of-Value Question: To what extent is a given state of affairs of basic intrinsic value for you?

Desire Satisfactionism, as it is usually understood, answers that the amount to which a given satisfied desire benefits the subject is proportional to the strength of the desire.

These are the two central questions theories of welfare need to answer. Desire Satisfactionism gives, at least initially, plausible-sounding answers to both. This explains its prominence. Still, questions remain. One that is particularly vexing for Desire Satisfactionism is the

Timing Question: At what time do you benefit from the obtaining of a given state of affairs? ${ }^{1}$

1 For more on why the Timing Question poses problems for Desire Satisfactionism, see Brad- 
To this question, Desire Satisfactionism lacks a stock answer.

In this essay, I criticize an intriguing answer to the Timing Question-asymmetrism - proposed recently by Eden Lin. ${ }^{2}$ I proceed in four sections. The first motivates asymmetrism. The second explains how Lin arrives at the final formulation of the view. The third argues that asymmetrism forces us to give implausible answers to the Magnitude-of-Value Question. The fourth section concludes.

\section{MOTIVATING ASYMMETRISM}

The best way to motivate asymmetrism is through cases where the time of desire and the time at which the object of the desire obtains do not overlap. So first consider

Speech Yesterday: Last night you gave an important speech. This morning you woke up and could not remember whether you thanked the host. As you lay in bed, you desire that you thanked the host. In fact, though you were so nervous you had no desire to do so, out of habit you did thank the host. We can visualize this desire satisfaction as follows.

\begin{tabular}{l|l|l} 
& Yesterday & Today \\
\hline Desire & & \\
Object & &
\end{tabular}

Assume that you do benefit from the satisfied desire in Speech Yesterday. When do you benefit - at the time of the desire (today) or the time of the object (yesterday)? The answer seems to be that, if you indeed benefit, the time at which you benefit is today. You did not benefit last night because you did not, at that time, have the desire to thank the host. You cannot be made better off by a satisfied desire prior to your having the desire. ${ }^{3}$

ley, Well-Being and Death; and Heathwood, "Desire Satisfactionism and Hedonism," 539-63.

Lin, "Asymmetrism about Desire Satisfactionism and Time." It is worth stressing that Lin does not endorse asymmetrism. His modest claim is that it is the best version of desire-satisfactionism that accommodates the idea that you can benefit at a time from the satisfaction of your desire even if there is no temporal overlap between the desire and its object. Lin is thus neutral on the relative merits of asymmetrism and concurrentism-the view that "you benefit from the satisfaction of a desire that you have during $t$ whose object obtains during $t^{*}$ at all and only those times when the desire and its object overlap" (165). Further, both of these views are compatible with a number of answers to the different question: "How must $t$ and $t^{*}$ be related in order for you to benefit from the satisfaction of your desire?" (164). For clear statements of Lin's modest aims, see 162, 182.

3 Lin, "Asymmetrism about Desire Satisfactionism and Time," 167. 


\section{Next consider}

Publication Tomorrow: Today you are thinking about the paper you have under review. You desire now that the paper is accepted tomorrow. Tomorrow your paper will be accepted. Sadly, tomorrow you will be hit with a bout of depression that saps you of this desire. We can visualize this desire satisfaction as follows.

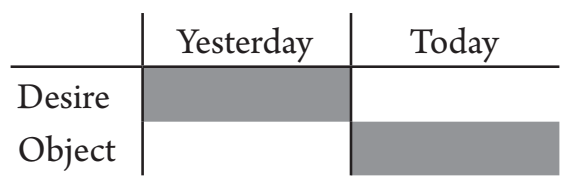

Assume that you do benefit from the satisfied desire in Publication Tomorrow. When do you benefit? At the time of the desire (today) or the time of the object (tomorrow)? The answer seems to be that, if you indeed benefit, the time at which you benefit is tomorrow. You did not benefit today because, at that time, your paper was not yet accepted. You cannot be made better off by a satisfied desire prior to the object of your desire obtaining. ${ }^{4}$

The upshot from Speech Yesterday is that, intuitively, when past-directed desires are satisfied, the time interval during which you benefit is the time of the desire. The upshot from Publication Tomorrow is that, intuitively, when future-directed desires are satisfied, the time interval during which you benefit is the time when the object obtains. Lin argues that a pair of powerful theoretical claims undergird these intuitions. His first claim we can call the

All-Necessary-Conditions Principle: You do not receive a particular benefit at $t$ unless, at $t$, all of the necessary conditions on your receiving that benefit have been met. $^{5}$

This principle is a narrower version of the general idea that a state of affairs does not obtain at a given time unless, at that time, all of the necessary conditions on that state of affairs' obtaining have been met. ${ }^{6}$ For example, suppose your baby will eventually have a child. Obviously enough, your baby is not now a parent. Why? Because, now, one of the necessary conditions-your baby's having a child-has yet to be met. If we accept the All-Necessary-Conditions Principle, we can similarly explain our intuitions in Speech Yesterday and Publication Tomorrow. For past-directed desires, the benefit interval cannot start until the

4 Lin, "Asymmetrism about Desire Satisfactionism and Time," 167.

5 Lin, "Asymmetrism about Desire Satisfactionism and Time," 169.

6 Lin, "Asymmetrism about Desire Satisfactionism and Time," 170. 
subject has the desire. For future-directed desires, the benefit interval cannot start until the object of the desire obtains.

On to Lin's second theoretical claim. We can call this the

Certainty-for-Benefit Principle: You do not receive a particular benefit at $t$ unless, for each of the necessary conditions on your receiving that benefit, the chance at $t$ that this condition will have been met by some time is $1 .^{7}$

In support of this principle, Lin argues that, if you are receiving some benefit now, then the chance at present that you are receiving this benefit is 1 . And this implies that, for any necessary condition on your receiving the benefit, the chance now that this condition will have been met by some time is 1 . Assuming that the future is open-i.e., "for the most part, if something might happen at a future time $t$, then presently, the objective chance that it will happen at $t$ is between $o$ and 1 "-the Certainty-for-Benefit Principle explains the intuitions elicited in Speech Yesterday and Publication Tomorrow. ${ }^{8}$ Why? Because, for past-directed desires, the benefit interval cannot start until the subject has the desire, as any time prior will put the chance of having this desire somewhere between $o$ and 1 , and because, for future-directed desires, the benefit interval cannot start until the object of the desire obtains, as any time prior will put the chance of this object obtaining somewhere between $\mathrm{o}$ and 1.

If we want to accommodate the idea that you can be benefited by past- and future-directed desire satisfactions, we are thus led to an asymmetry: "If the time at which you have a desire is later than the time at which its object obtains, then you benefit at the time of the desire. If the time of object is later than the time of desire, then you benefit at the time of object." ${ }^{\prime 9}$ This is, very roughly, asymmetrism.

\section{REFINING ASYMMETRISM}

But complications remain. We have been focusing on cases where the desire and the object never temporally overlap. What should we say when they do? Lin's sensible proposal is that the benefit interval begins at the first time you have the desire and its object obtains, and the benefit interval ends at the latest time when either you have the desire or its object obtains. ${ }^{10}$

This suggestion has much appeal. To see why, consider

8 Lin, "Asymmetrism about Desire Satisfactionism and Time," 172.

9 Lin, "Asymmetrism about Desire Satisfactionism and Time," 162.

10 Lin, "Asymmetrism about Desire Satisfactionism and Time," 177-78. 
Patriotism: Inspired by the opening ceremony for the Olympics, on Monday you form the desire that your country holds the most all-time gold medals. This desire persists until Wednesday, when you grow bored of the Olympics entirely. In the meantime, on Tuesday, your country comes to hold the most all-time gold medals. However, another country surpasses your country's count on Friday at midnight, and your country never regains the lead. We can visualize this desire satisfaction as follows.

\begin{tabular}{l|c|c|c|c|c|c|c} 
& $\mathrm{M}$ & $\mathrm{Tu}$ & $\mathrm{W}$ & $\mathrm{Th}$ & $\mathrm{F}$ & $\mathrm{Sa}$ & $\mathrm{Su}$ \\
\hline $\begin{array}{l}\text { Desire } \\
\text { Object }\end{array}$ & & & & & & &
\end{tabular}

Assume that you do in fact benefit from the satisfied desire in Patriotism. How long do you benefit? Since when you begin seems obvious—on Tuesday-the real question is when you stop. Lin argues that, despite losing your desire starting Thursday, you benefit through Friday. His reasoning is persuasive: "if the interval during which [you] desired [that your country holds the most all-time gold medals] had occurred a month ago, asymmetrism would say that [you] benefit exactly when the object of [your] desire obtains-namely, from Tuesday through Friday. It would be bizarre if, in the case where [you] have the desire from Monday through Wednesday, [you] benefit during a different interval (e.g., from Tuesday through Wednesday)."11 The same line of thought, mutatis mutandis, applies to cases of overlap in which the interval of the desire ends later than the interval of the object.

But here a new issue arises. Consider a revised version of the previous case:

Death: Things are just as described in Patriotism, except that you do not lose your desire on account of growing bored with the Olympics. Rather you die on Wednesday at midnight.

Should we still treat the time interval as extending from Tuesday through Friday? The answer seems to be no. Most of us, with Lin, balk at benefits that are received at posthumous times. ${ }^{12}$ And so, if we want to rule out the possibility of benefits that are posthumously accrued, we need to keep the benefit interval within the times you are alive.

With these refinements, we arrive at Lin's final formulation of

Asymmetrism: You begin to benefit from the satisfaction of a desire at the earliest time at which (i) you exist, and (ii) you have had the desire and its

Lin, “Asymmetrism about Desire Satisfactionism and Time," 176.

Lin, “Asymmetrism about Desire Satisfactionism and Time," 180-81. 
object has obtained. You cease to benefit from the satisfaction of a desire at the latest time at which (i) you exist and (ii) either you have the desire or its object obtains. ${ }^{13}$

This formulation, on the assumption that you are benefited in all the above cases, gives us very plausible results. It fits our intuitions in Speech Yesterday and Publication Tomorrow. But clause (i) ensures that, in Death, the benefit interval ceases on Wednesday at midnight. And clause (ii) ensures that, in Patriotism, the benefit interval extends until Friday. Moreover it conforms to the All-Necessary-Conditions Principle and the Certainty-for-Benefit Principle. I thus take this to be the definitive version of asymmetrism.

\section{ASYMMETRISM AND THE MAGNITUDES OF BENEFITS}

So much for what is appealing about asymmetrism. Now for what is unappealing. Thus far we have been ignoring the Magnitude-of-Value Question. In this section, I will argue that asymmetrism cannot give us plausible answers. To get there, however, we need to make a fairly uncontroversial assumption. This assumption holds that the extent to which you benefit from a satisfied desire tracks the strength of the desire. Put precisely, we should assume

Strength Proportionalism: The magnitude of the benefit you receive from a given satisfied desire matches, at least in some respect, the strength of the desire.

This assumption reflects the common idea that the amount of intrinsic value for you of a satisfied desire is equal to the strength of the desire. Note that Strength Proportionalism, given the "in some respect" clause, is modest. It claims only that the proportionality between amount of benefit and strength of the satisfied desire needs to be reflected somewhere in the answer to the Magnitude-of-Value Question. As we will see, this clause allows for more than one version of asymmetrism to be consistent with Strength Proportionalism.

With this assumption in place, we can turn to one answer that asymmetrism might give to the Magnitude-of-Value Question. Consistent with Strength Proportionalism, we could hold that the total intrinsic value for you of a satisfied desire is equal to the strength of the desire. And then hold that the total intrinsic value is evenly distributed over the benefit interval. ${ }^{14}$ Return to Patriotism, and

14 I take it that, for each moment of the benefit interval, the agent must receive a nonzero welfare increase. That is, if you benefit from a satisfied desire from $t$ to $t^{*}$, then this desire 
let us stipulate that the strength of your satisfied desire is 12. On this proposal, then, your total benefit is 12 units of well-being. And, since the benefit interval is four days, for each day, you benefit 3 units of well-being. We can visualize this as follows.

\begin{tabular}{c|c|c|c|c|c|c|c} 
& $\mathrm{M}$ & $\mathrm{Tu}$ & $\mathrm{W}$ & $\mathrm{Th}$ & $\mathrm{F}$ & $\mathrm{Sa}$ & $\mathrm{Su}$ \\
\hline Benefit & $\mathrm{o}$ & 3 & 3 & 3 & 3 & $\mathrm{o}$ & $\mathrm{o}$
\end{tabular}

This result seems, at first blush, plausible. Since this view works by spreading the total benefit - which here we treat as proportional to the strength of the desire satisfied-across the interval, let us call this Diachronic-Payout Asymmetrism.

Diachronic payments are what might first come to mind when thinking about how asymmetrism might answer the Magnitude-of-Value Question. A moment's reflection, however, reveals that this answer suffers serious problems. By adjusting the benefit interval, the very same desire satisfaction will deliver different synchronic payouts. If the benefit interval is shorter, for example, the distribution of the total benefit will need to be squeezed into fewer units of time. To see why this is counterintuitive, return to Death. In terms of your desire, nothing changes in this case from Patriotism. You still have the desire Monday through Wednesday and it is still of strength 12. Yet your death makes a surprising difference to your Tuesday and Wednesday. Though they are, in Patriotism and Death, identical states of affairs, Diachronic-Payout Asymmetrism implies that Tuesday and Wednesday are better for you in Death than they are in Patriotism. Why? Because there are two fewer days, in Death, to spread out the total benefit. We can visualize the benefit in Death as follows.

\begin{tabular}{c|c|c|c|c|c|c|c} 
& $\mathrm{M}$ & $\mathrm{Tu}$ & $\mathrm{W}$ & $\mathrm{Th}$ & $\mathrm{F}$ & $\mathrm{Sa}$ & $\mathrm{Su}$ \\
\hline Benefit & $\circ$ & 6 & 6 & $\circ$ & $\circ$ & $\circ$ & $\circ$
\end{tabular}

This result is hard to believe. Your Tuesday and Wednesday do not get better for you in Death than in Patriotism. ${ }^{15}$

Beyond this counterintuitive result, Diachronic-Payout Asymmetrism's handling of Death and Patriotism allows us to see a more damning problem. The

satisfaction makes you uninterruptedly better off from $t$ to $t^{*}$-i.e., you receive at least some benefit at each unit of time during this interval. This claim strikes me as trivially true, following from the very meaning of "you benefit from a satisfied desire from $t$ to $t^{*}$." I thank an anonymous reviewer for pressing me to clarify this point.

15 You could, it is worth noting, get this result without death. For example, suppose things are as described in Patriotism, but your country's gold medal count is overtaken a day earlier. In that case, we would get the result that you benefited 4 units of well-being per day rather than 3 . 
view violates the Certainty-for-Benefit Principle. For notice, this variation of asymmetrism implies that the magnitude of the benefit that you receive now can depend on what happens in the future. In most cases, at the beginning of a benefit interval, the future is open with respect to how long the subject will continue benefiting. If the interval of the desire comes after the end of the interval of the object, then, at the beginning of the interval of the desire, the future is open with respect to how long the benefit interval will be. It depends on the length of the interval of the desire. If the interval of the object comes after the end of the interval of the desire, then, at the beginning of the interval of the object, the future is open with respect to how long the benefit interval will be. It depends on the length of the interval of the object. In Death, on Tuesday the future is open with respect to when the object of the desire will cease to obtain and with respect to when the subject will die. Accordingly, your receiving the particular benefit - 6 units of well-being - on Tuesday depends, at that time, on states of affairs whose objective probability of obtaining lies between o and 1. Diachronic-Payout Asymmetrism is at odds with one of the main theoretical motivations for accepting asymmetrism. Hence anyone who accepts asymmetrism on account of the Certainty-for-Benefit Principle would deny that the magnitude of the benefit that you receive now can depend on what happens in the future. ${ }^{16}$ Diachronic-Payout Asymmetrism should be rejected.

We can next turn to a second plausible way that asymmetrism might answer the Magnitude-of-Value Question. Consistent with Strength Proportionalism, we could hold that the intrinsic value for you of a satisfied desire is equal to the strength of the desire for each unit of time during the benefit interval. Return again to Patriotism. On this proposal, since you have a satisfied desire of strength 12, you are benefited 12 units of well-being for each moment of the benefit interval. Let us set aside complications about how units of time might be divided and just stick with days. ${ }^{17}$ We thus get the following payout for Patriotism.

\begin{tabular}{c|c|c|c|c|c|c|c} 
& $\mathrm{M}$ & $\mathrm{Tu}$ & $\mathrm{W}$ & $\mathrm{Th}$ & $\mathrm{F}$ & $\mathrm{Sa}$ & $\mathrm{Su}$ \\
\hline Benefit & $\mathrm{O}$ & 12 & 12 & 12 & 12 & $\mathrm{O}$ & $\mathrm{O}$
\end{tabular}
er for stressing its importance and for the wording of some parts of this paragraph.

If an interval is infinitely divisible and we are forced to assign a nonzero amount to each division, then any desire satisfaction (whatever the strength) would yield infinite value for you. I am here simply going to assume this problem can be solved. Hence, I assume that the number of units of time assigned a benefit for a given interval is finite. With this assumption made, nothing important in the argument to come hinges on how we divide up the units. So, for ease of exposition, I will stick with days. 
This result is promising. Since this view works by repeatedly giving a benefitproportional to the strength of the desire-at each moment of the interval, let us call this Synchronic-Payout Asymmetrism.

This view marks an improvement on its diachronic cousin. ${ }^{18}$ It does not, in Death, adjust the magnitude of benefit you receive on Tuesday and Wednesday, nor does it violate the Certainty-for-Benefit Principle. Yet it too faces a serious problem. To see the worry, note how Synchronic-Payout Asymmetrism arrives at the total benefit. For Diachronic-Payout Asymmetrism, recall, the strength of the desire determines the total benefit, irrespective of the benefit interval. Accordingly, the total magnitude of the benefit conferred by a satisfied desire is reined in by that desire's strength. By contrast, for Synchronic-Payout Asymmetrism, the total benefit is a function of the strength of the satisfied desire and the length of the benefit interval. For a given satisfied desire, its total benefit is greater the longer the benefit interval. This implies that even a very weak satisfied desire, so long as it has an incredibly long interval, can yield an enormous benefit.

To see why this implication is counterintuitive for any version of asymmetrism, it is worth remembering that asymmetrism allows a benefit interval to extend beyond the time at which the agent ceases to have the desire. Keeping this in mind, a set of contrast cases will make the worry vivid. Start with

Not Alone: When you were five years old, you read a book about space travel. You found it mildly interesting, and formed an extremely weakstrength 1 -desire that we are not alone in the universe. This desire persists until your death. And, in fact, other beings have existed in the universe from before you were born and continue to exist until after your death.

Synchronic-Payout Asymmetrism tells us that, in this case, though the strength of your satisfied desire is very weak, the magnitude of the benefit it confers is huge. If you live to seventy-five years old, for example, the benefit will be over twenty-five-thousand units of well-being. ${ }^{19}$ Using this implication of Not Alone

In correspondence, Lin said he is inclined toward accepting Synchronic-Payout Asymmetrism. But he expressed reservations based, in part, on the problem raised below.

19 What is troubling about Synchronic-Payout Asymmetrism, I should stress, is not that it allows a very minor benefit per unit of time had for a very long time to outweigh a very great benefit per unit of time had for a very short time. Rather the problem I am pressing concerns the undue evaluative significance of the length of the benefit interval, as determined by asymmetrism, on the magnitude of the benefit. This problem would thus not apply to, for example, a synchronic payout version of a Time of Desire view, which holds roughly that you benefit from a satisfied desire at all and only those times when you have the desire (Lin, "Asymmetrism about Desire Satisfactionism and Time," 165). Since the Time of Desire view 
as a baseline, we can see that the magnitude of a total benefit should not depend on the length of the benefit interval, as determined by asymmetrism, by considering a variation on the case.

Dropped Quickly: Things are just as described in Not Alone, except that the next day you cease having the desire. You are, the day after and for every day until your death, entirely indifferent to whether or not other beings exists in the universe.

According to asymmetrism, you start the benefit interval at the earliest time at which you have both the desire and its object obtains, and the benefit interval stops at the latest time at which either you have the desire or its object obtains. Hence, in Dropped Quickly, since we are not alone, the benefit interval begins the day you form the desire. And, since other beings exist in the universe until after your death, the benefit interval lasts until you die. The benefit interval is, in other words, identical in Not Alone and Dropped Quickly. Synchronic-Payout Asymmetrism thus tells us that the total benefit you receive is the same in both cases.

It is hard to believe that the amount of benefit conferred by a satisfied desire continues to increase at the same rate regardless of whether the desire has been abandoned. But this is precisely what Synchronic-Payout Asymmetrism claims to be the case. It should be rejected. The magnitude of the benefit from a given satisfied desire should not be tied to the duration of the benefit interval, as determined by asymmetrism, because asymmetrism allows this interval to extend beyond the duration of the desire. ${ }^{20}$

\section{CONCLUSION}

Asymmetrism is a very attractive view for those who want to accommodate the idea that you benefit when there is no temporal overlap between a desire and its object. But it seems forced to give very unattractive answers to the Magnitude-of-Value Question. Diachronic-Payout Asymmetrism and Synchronic-Pay-

ties the benefit interval to the duration of the desire, a synchronic payout version would yield different-sized benefits in Not Alone and Dropped Quickly. Incidentally, it seems unobjectionable, on a Time of Desire view, for a very weak satisfied desire with a very long benefit interval to yield a benefit greater than a very strong satisfied desire with a very short benefit interval. This seems unobjectionable because, once again, the Time of Desire view links the benefit interval to the possession of the relevant desire, and because of the familiar sequence arguments found, for example, in Norcross, "Comparing Harms." I thank an anonymous reviewer for flagging this potential misunderstanding.

I am indebted to an anonymous reviewer for the wording here. 
out Asymmetrism seem to be the only plausible views consistent with Strength Proportionalism. But both these versions of asymmetrism should be rejected. Thus to avoid giving implausible answers to the Magnitude-of-Value Question, asymmetrism seems required to abandon Strength Proportionalism. This is not a welcome position. Desire satisfactionists should perhaps look elsewhere for the answer to the Timing Question. ${ }^{21}$

Nanyang Technological University forcehimes@ntu.edu.sg

\section{REFERENCES}

Bradley, Ben. Well-Being and Death. Oxford: Oxford University Press, 2009.

Heathwood, Chris. "Desire Satisfactionism and Hedonism." Philosophical Studies 128, no. 3 (April 2006): 539-63.

Lin, Eden. "Asymmetrism about Desire Satisfactionism and Time." Oxford Studies in Normative Ethics, vol. 7, edited by Mark C. Timmons, 161-83. Oxford: Oxford University Press, 2017.

Norcross, Alastair. "Comparing Harms: Headaches and Human Lives." Philosophy and Public Affairs 26, no. 2 (April 1997): 135-67.

21 This paper would not have been written without Eden Lin's help and encouragement. Most of the ideas here were presented to him in crude form, and he took a great deal of his own time to refine them into something much better. It is rare to find a philosopher so eager to criticize his own work. I would also like to think Winnie Sung and Luke Semrau for helpful comments on earlier drafts. 